\title{
Optimization for energy efficiency of underground building envelope thermal performance in different climate zones of China
}

\author{
Luyang Shi ${ }^{1}$, Jing Liu ${ }^{1, *}$, and Huibo Zhang $^{2}$ \\ ${ }^{1}$ School of Municipal and Environmental Engineering, Harbin Institute of Tech, 202 Haihe Street, \\ Nangang District, Harbin, China \\ ${ }^{2}$ School of Naval Architecture, Ocean and Civil Engineering, Shanghai Jiao Tong University, 800 \\ Dongchuan Road, Minhang District, Shanghai, China
}

\begin{abstract}
The object of this article is to investigate the influence of thermal performance of envelopes in shallow-buried buildings on energy consumption for different climate zones of China. For the purpose of this study, an effective building energy simulation tool (DeST) developed by Tsinghua University was chosen to model the heat transfer in underground buildings. Based on the simulative results, energy consumption for heating and cooling for the whole year was obtained. The results showed that the relationship between energy consumption and U-value of envelopes for underground buildings is different compared with above-ground buildings: improving thermal performance of exterior walls cannot reduce energy consumption, on the contrary, may result in more energy cost. Besides, it is can be derived that optimized U-values of underground building envelopes vary with climate zones of China in this study. For severe cold climate zone, the optimized U-value of underground building envelopes is $0.8 \mathrm{~W} /\left(\mathrm{m}^{2} \cdot \mathrm{K}\right)$; for cold climate zone, the optimized U-value is $1.5 \mathrm{~W} /\left(\mathrm{m}^{2} \cdot \mathrm{K}\right)$; for warm climate zone, the U-value is $2.0 \mathrm{~W} /\left(\mathrm{m}^{2} \cdot \mathrm{K}\right)$.
\end{abstract}

\section{Introduction}

The global contribution from buildings towards energy consumption has steadily increased with urbanization ([1]). And underground building is one of big energy consumer and has significant impacts on energy consumption ([2]). The optimization design of energy saving for buildings below ground is also extremely important.

Generally, building envelope features considerably affect the energy efficiency of buildings ([3], [4]). For above-ground buildings, the reduction of energy consumption could be generated by improving thermal performance of the envelopes. However, underground buildings are more advantageous for their better capacity of heat storage, heat stability and smaller variation of temperature ([5]). The heat transfer through underground building envelopes maybe different compared with above-ground buildings.

\footnotetext{
* Corresponding author: liujinghit0@163.com
} 
The aim of this study is to investigate the influence of thermal performance of envelopes on energy consumption for underground buildings. The heat transfer within underground buildings was simulated using energy simulation tool DeST and the energy cost was also calculated based on the standards of energy efficiency evaluation ([6]). In addition, the optimal U-values of envelopes in underground for different climate zones of China were determined and intercompared for the purpose of building energy-efficiency

\section{Simulation model for underground buildings}

\subsection{DeST}

In this study, an effective building energy simulation tool (DeST) developed by Tsinghua University was selected. DeST simulation model is a dynamic building thermal process model which can be used to calculate the heat transfer through the building components and energy consumption yearly.

The modeling process of DeST is to perform a discrete solution for the equations of heat energy conservation. Since the nodes on the exterior surface of envelopes are in direct contact with soil, these nodes must do some special handing. In DeST, the heat transfer between exterior surface of envelopes and surrounding soil can be solved by the method of frequency domain ([7]). The heat government equation for these nodes can be written in Eq.(1).

$$
c_{p} \rho \frac{d t_{i}}{d \tau} \frac{\Delta x_{i}}{2}=Q_{i}(\tau)+\frac{K_{i}}{\Delta x_{i}}\left(t_{i}-t_{i+1}\right)
$$

Where, $\mathrm{c}_{\mathrm{p}}$ is the specific heat capacity of indoor air, $\mathrm{J} /\left(\mathrm{kg} \cdot{ }^{\circ} \mathrm{C}\right) ; \rho$ is the density of indoor air, $\mathrm{kg} / \mathrm{m}^{3} ; \mathrm{t}_{\mathrm{a}}$ is the temperature of indoor air, ${ }^{\circ} \mathrm{C} ; \mathrm{K}_{\mathrm{i}}$ is the heart transfer coefficient between soil and the surface of wall $i, \mathrm{~W} /\left(\mathrm{m}^{2} \cdot \mathrm{K}\right) ; \mathrm{t}_{\mathrm{i}}, \mathrm{t}_{\mathrm{i}+1}$ represents the temperature of the exterior surface of the wall $i$ and the soil, respectively, ${ }^{\circ} \mathrm{C} ; \Delta x_{i}$ is the thickness of discrete layer, $\mathrm{m} ; \tau$ is the calculated time, $\mathrm{s}$.

In Eq.(1), $Q_{i}(\tau)$ represents heat flux transferred into buildings from surrounding soil, which can be calculated in Eq.(2) using state space method.

$$
Q_{i}(\tau)=\text { his_g_disturb }+t_{i}(\tau) t_{i}(\tau) \sum_{j} g \varphi_{i j, 0}
$$

Where, his_g_disturb is related to thermal disturbance and thermo-physical property of underground building. And his_g_disturb is a determined quantity for calculated time $\tau . \sum_{j} g \varphi_{i j, 0}$ is constant and determined by thermo-physical property of the system.

Therefore, the energy conversation equation for these special nodes on the exterior surface of envelopes can be written in Eq.(3).

$$
c_{p} \rho \frac{d t_{i}}{d \tau} \frac{\Delta x_{i}}{2}=\text { his_g_disturb }+t_{i}(\tau) \sum_{j} g \varphi_{i j, 0}+\frac{K_{i}}{\Delta x_{i}}\left(t_{i}-t_{i+1}\right)
$$

\subsection{Simplified model of underground building}

In this simulation, the complex underground building is assumed as a simple building composed of three rooms of same size $(4.0 \times 4.0 \times 3.3 \mathrm{~m})$. Fig. 1 shows the layout of underground building with $3.0 \mathrm{~m}$ depth below the ground. The calculated building is surrounded by rammed clay considered a sort of special component of exterior walls. The thermal conductivity coefficient of rammed clay is $1.16 \mathrm{~W} /(\mathrm{m} \cdot \mathrm{K})$. 


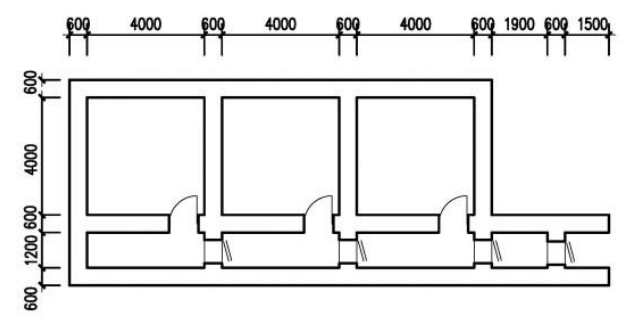

Fig. 1. The layout of simplified underground building

The U-value of underground building envelopes is set based on design standard for energy efficiency of public buildings ([6]). Table 1 shows design standard of thermal performance of envelops for different climate zones of China. Since the heat transfer in underground building and above-ground building is different, design standard of thermal performance of envelops may have different values. The U-value of exterior wall were set in the range of $0.2 \sim 3.0 \mathrm{~W} /(\mathrm{m} \cdot \mathrm{K})$ for the purpose of investigating the effect of U-value of exterior wall on the energy consumption.

Table 1. Design standard of U-values of envelops for different climate zones

\begin{tabular}{|c|c|}
\hline Climate zone & U-value $\left(\mathrm{W} /\left(\mathrm{m}^{2} \cdot \mathrm{K}\right)\right)$ \\
\hline Severe cold zone & $\leq 0.35$ \\
\hline Cold zone & $\leq 0.50$ \\
\hline Hot summer and cold winter zone & $\leq 0.60$ \\
\hline Hot summer and warm winter zone & $\leq 0.80$ \\
\hline Temperate climates zone & $\leq 0.8$ \\
\hline
\end{tabular}

\subsection{Description of modelling parameter and weather condition}

Compared with ground buildings, underground buildings have excellent properties such as large capacity of heat storage, and good airtightness. These properties help to keep underground space warm in the winter and cool in the summer. And the indoor temperature in underground is lower than $20{ }^{\circ} \mathrm{C}$ in sometimes during summer, and then the room need be heated. Thus, the indoor climate conditions for underground buildings may be set a wide comfortable range. According to the references about ground buildings, indoor temperature for underground buildings in summer and winter was set in a wide range of $20 \sim 28^{\circ} \mathrm{C}$, $18 \sim 22^{\circ} \mathrm{C}$, respectively. The air conditioning was used to keep indoor temperature at the set range. The sources of heat and humidity, including people, equipment and lightings, were set based on references of typical office buildings ([7]). And the ventilation was not taken into account in this simulation in order to remove the impacts of fresh air on building loads.

The weather data is used as representative of typical weather variations. Twelve typical cities selected from different climate zones of Chin were studied in this simulation (Fig. 2). 


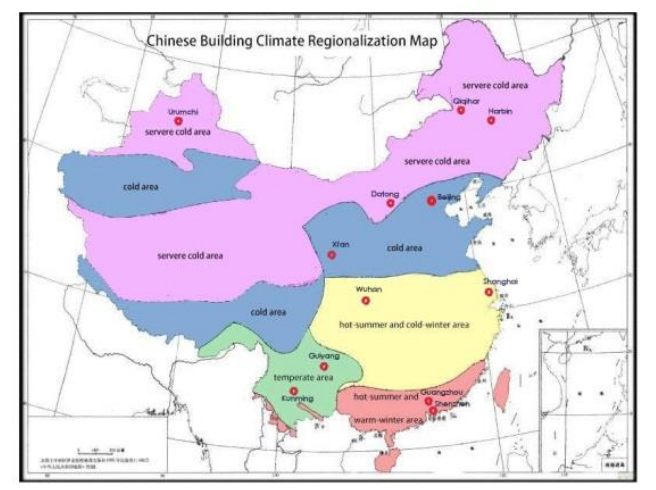

Fig. 2. The map of climate zones in China and location of twelve typical cities

\section{Results \& discussion}

Generally, enhancing thermal performance of envelopes is beneficial for above-ground building because of reduction of heat loss from building envelopes. However, for underground buildings, raising the thermal performance of the envelopes cannot reduce energy consumption, on the contrary, may result in more energy cost. These differences are supposed to be due to large capacity of heat storage of underground buildings which helps to keep the room warm in the winter and cool in the summer.

In summer, decreasing U-value of envelopes can transfer more heat into the surrounding soil effectively, which is helpful to drop indoor temperature significantly. In winter, thermal resistance of exterior walls can effectively prevent heat from transferring into the surrounding soil. But, if U-value of envelopes is too small, the heat generated in the room cannot transfer into soil effectively, even leading to cooling load in winter. In terms of energy conservation, it is not reasonable and available. Therefore, there is a trade-off when the thermal performance of exterior walls of underground buildings is designed for the purpose of energy conversation.

Relationship between energy consumption and heat transfer coefficients of envelopes for different climate zones is plotted in Fig.3, respectively. It is observed that the shapes of the curves which both have single valley in Fig. 3 are similar. 


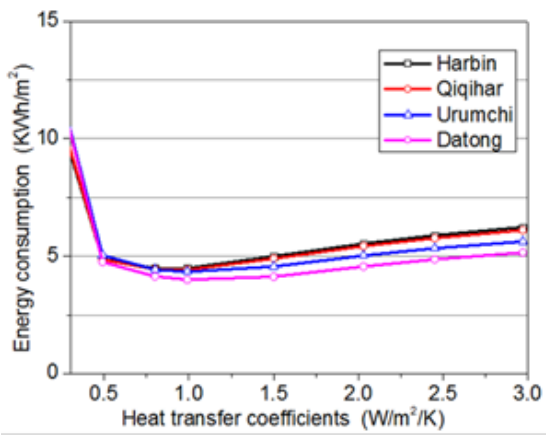

(a)

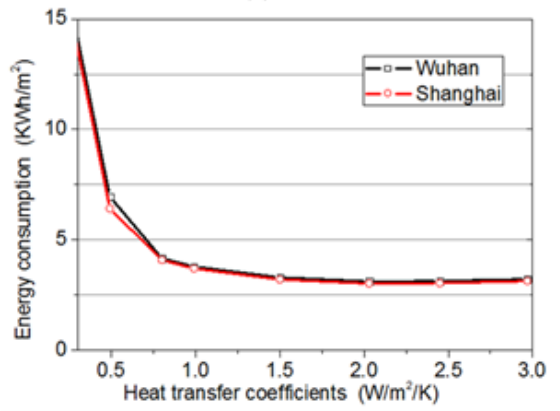

(c)

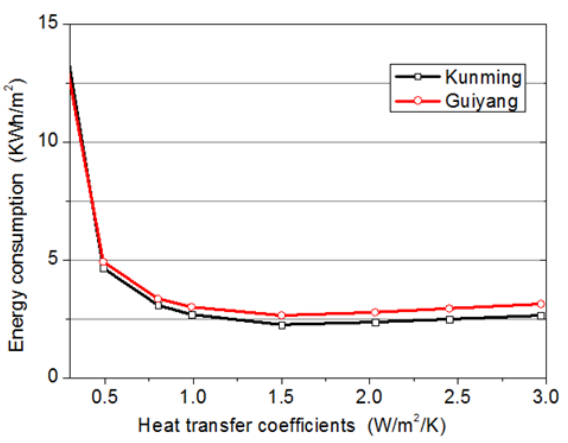

(e)

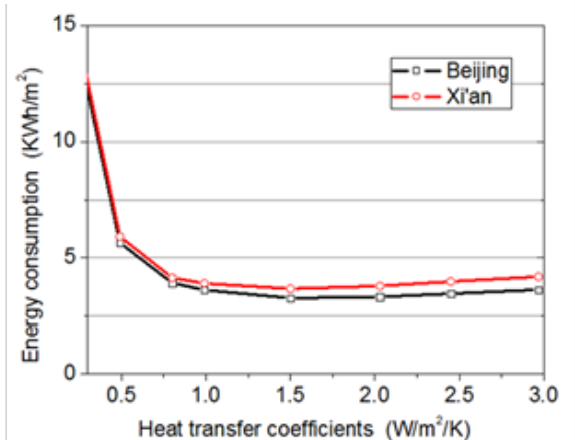

(b)

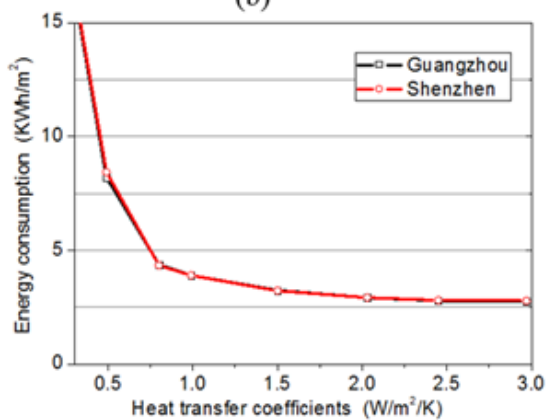

(d)

Fig. 3. Relationships between energy consumption and U-value for different climate zones of China

Fig.3 (a) shows calculated results in severe cold climate zone. It is noted that increasing the heat transfer coefficient of envelopes from $0.22 \mathrm{~W} /\left(\mathrm{m}^{2} \cdot \mathrm{K}\right)$ to $1.0 \mathrm{~W} /\left(\mathrm{m}^{2} \cdot \mathrm{K}\right)$ tends to reduce the sum of energy used for heating and cooling, whereas the energy consumption increases when the heat transfer coefficient increases continuously from $1.0 \mathrm{~W} /\left(\mathrm{m}^{2} \cdot \mathrm{K}\right)$. Therefore, energy-efficient optimized value of underground envelopes for bitter cold climate zone is $1.0 \mathrm{~W} /\left(\mathrm{m}^{2} \cdot \mathrm{K}\right)$. Similarly, it is can be derives that energy-efficient optimized value of underground envelopes for cold climate zone is $1.5 \mathrm{~W} /\left(\mathrm{m}^{2} \cdot \mathrm{K}\right)$ from Fig.3 (b). From Fig.3 (c) Fig.3 (e), we observed that for other climate zones (including hot summer and cold winter zone, hot summer and warm winter zone, and temperate climates zone), optimized value of heat transfer coefficients are similar, thus the optimized value can be regard as the same value in the error-allowed range, $2.0 \mathrm{~W} /\left(\mathrm{m}^{2} \cdot \mathrm{K}\right)$.

The optimized values of underground envelopes in different climate zones are different. The major cause for this is the difference of the soil temperature around buildings.Fig.4 
presents measured data of the soil temperature with $3.2 \mathrm{~m}$ depth in underground in typical cities of different climate zones in China.

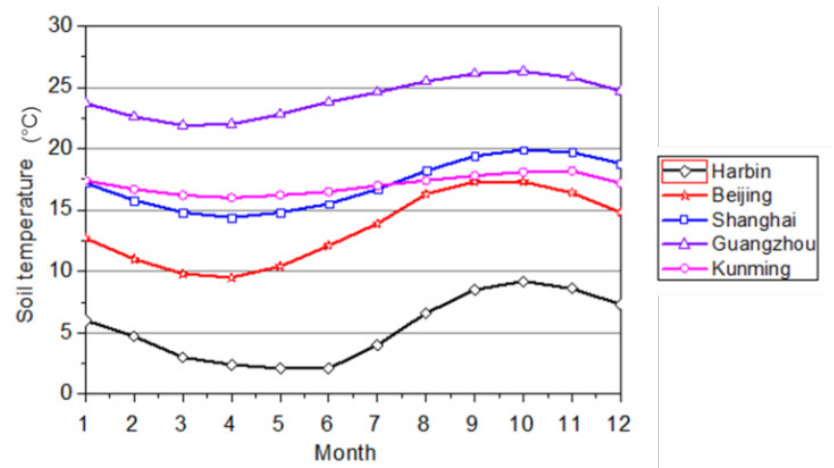

Fig.4. Measured data of the soil temperature of $3.2 \mathrm{~m}$ depth below the ground

From Fig.4, we observed that the fluctuation of soil temperature in Harbin and Beijing is bigger than other three cities. For Harbin, the average of soil temperature $(3.2 \mathrm{~m}$ depth below ground) is lowest among in all studied cities, about $5^{\circ} \mathrm{C}$, which account for basic requirements of good thermal insulation of envelopes below ground. For warm climate, the average soil temperature $\left(3.2 \mathrm{~m}\right.$ depth below the ground) is higher than $15^{\circ} \mathrm{C}$, especially in Guangzhou (the average soil temperature of $3.2 \mathrm{~m}$ depth below the ground reaches $24^{\circ} \mathrm{C}$ ). For theses climate zones, cooling the interior space is main factor to consider when the thermal performance of underground building envelopes is designed for the purpose of energy saving.

\section{Conclusions}

The effect of envelope thermal performance on energy consumption for shallow-buried buildings in different climate zones of China was investigated in this paper. DeST was used to simulate the heat transfer within building below the ground. And the energy consumption was also calculated according to the standards of building envelope thermal performance trade-off.

Because of large capacity of heat storage of underground buildings, effect of thermal performance of envelopes on energy consumption for ground building and underground building varies considerably. Raising thermal performance of envelopes below ground cannot reduce energy consumption, on the contrary, may result in more energy cost. When the thermal performance of envelopes in underground is designed for the purpose of building energy conversation, we should make a trade- off synthetically. Besides, it is can be derived that the optimized U-value for underground building envelopes is different in different climate zones of China. For severe cold climate zone, the optimized U-value is $0.8 \mathrm{~W} /\left(\mathrm{m}^{2} \cdot \mathrm{K}\right)$; for cold climate zone, the optimized value is $1.5 \mathrm{~W} /\left(\mathrm{m}^{2} \cdot \mathrm{K}\right)$; for warm climate zone, the optimized value is $2.0 \mathrm{~W} /\left(\mathrm{m}^{2} \cdot \mathrm{K}\right)$.

These conclusions are drawn for the buildings which are buried less than $5.0 \mathrm{~m}$ depth below the ground. A further work could be conducted to consider the buildings located more than $5.0 \mathrm{~m}$ depth below the ground in different climate zones of China.

This research was supported by Technology and Research Project of China State Construction Engineering Corporation (CSCEC-2014-Z-1-2-01). 


\section{References}

1. Pérez-Lombard, L., Ortiz, J., \& Pout, C. (2008). A review on buildings energy consumption information. Energy \& Buildings, 40(3), 394-398.

2. Casals, M., Gangolells, M., Forcada, N., Macarulla, M., \& Giretti, A. (2014). A breakdown of energy consumption in an underground station. Energy \& Buildings, 78(4), 89-97.

3. Nielsen, T. R. (2005). Simple tool to evaluate energy demand and indoor environment in the early stages of building design. Solar Energy, 78(1), 73-83.

4. Lin, Y. H., Tsai, K. T., Lin, M. D., \& Yang, M. D. (2016). Design optimization of office building envelope configurations for energy conservation. Applied Energy, 171, 336-346.

5. Shao-Hua, L. I., Shang, Z. H., Gong, M. Z., Wang, H. L., \& Kun, Y. E. (2012). Calculation of heat shortage capacity of soil temperature field around the pipeline in the preheating process of underground oil pipelines. Contemporary Chemical Industry.

6. Xie Xiaona, Jiang Yi. (2004).Study on heat transfer within underground for thermo physical model in DeST. The national HVAC academic annual meeting.

7. GB 50189-2015. (2015).Design standard for energy efficiency of public buildings. 